\title{
Sobre a disciplinarização da Literatura Regionalista Gaúcha: um pouco de história das idéias
}

\author{
Verli Fátima Petri da Silveira ${ }^{\circledR}$
}

\section{Introdução}

No presente trabalho, apresentamos algumas reflexões acerca do processo de disciplinarização da Literatura Regionalista Gaúcha, na Universidade Federal de Santa Maria, localizada na região central do estado do Rio Grande do Sul. Trata-se de uma abordagem teórico-metodológica, que estabelece relações entre os pressupostos da História das Idéias Lingüísticas ${ }^{1}$ e os pressupostos da Análise de Discurso, dita de Escola Francesa. Portanto, tomaremos esse processo de disciplinarização de um ponto de vista não-literário, mas que, ao mesmo tempo, permeia a produção literária, a sua circulação no meio acadêmico e as suas relações com a língua e com a construção da História das Idéias no sul do Brasil.

Tomemos como ponto de partida o início do século $\mathrm{XX}$, para contextualizar todo o processo. Trata-se do período marcado pela criação das primeiras Faculdades de Filosofia, Ciências e Letras, de onde emergiu a exigência e a obrigatoriedade do ensino de Literatura, de forma institucionalizada. A partir de então, a disciplina de Literatura torna-se obrigatória no ensino público brasileiro, valorizando perspectivas históricas e ajudando na consolidação da nacionalidade (PEDROSA, 2000).

Sob esta atmosfera, o Curso de Letras funcionou, durante muito tempo (juntamente com o curso de Filosofia), como um desencadeador de processos de institucionalização de universidades, no interior do País. Isso ocorria com muita freqüência, porque as universidades tinham início com cursos da área das

\footnotetext{
(C) A presente edição de Fragmentum é resultado parcial do Projeto "A Literatura Regionalista Gaúcha na História das Idéias Lingüísticas", que recebeu apoio da FAPERGS/RS, pela modalidade ARD, em 2006-2007.

1 Este trabalho se inscreve num projeto maior e integra as pesquisas do Laboratório Corpus/UFSM, sob Coordenação da Prof ${ }^{a}$. Dra ${ }^{\text {. }}$. Amanda Eloina Scherer.
} 
Ciências Humanas, que exigiam instalações físicas simples e que tinham boa aceitação da comunidade, uma vez que vinham atender a demandas locais, como a formação de professores (e eventualmente de religiosos). Os currículos dos cursos de Letras traziam disciplinas da área de Literatura, de Lingüística, de Língua Portuguesa e de Línguas Estrangeiras, bem como as disciplinas de cunho pedagógico. É importante salientar que era junto às disciplinas de Línguas e de Literaturas que se desenvolvia a parte de formação cultural e identitária dos acadêmicos, não só reforçando o nacionalismo, como também desenvolvendo já o gosto pelo regionalismo, e abrindo espaço para o estudo da produção literária local.

Atualmente, as demandas são outras, e os cursos de formação de professores, sobretudo os de Línguas e os de Literaturas, não são de alta prioridade para o Estado que, por sua vez, não se preocupa mais tanto com a formação identitária de um país, que já completou 500 anos de seu "descobrimento", mas sim com a sua inserção no cenário do mundo globalizado. Essa mudança de interesses do Estado brasileiro vem refletir também na reestruturação dos cursos de Letras pelo Brasil afora. Poderíamos discorrer longamente sobre as reformulações curriculares que assolam a nossa era contemporânea, porém nos deteremos apenas em observar como se alteram os espaços destinados à Literatura Regionalista Gaúcha e, de modo particular, como se dá sua presença/ausência nos currículos da Universidade Federal de Santa Maria (UFSM). E, para tanto, tomamos como premissa a seguinte afirmação: "a história de uma disciplina tem sua origem, de um lado, na história das idéias; de outro lado, na história das instituições, que ajudaram a constituí-la" (SCHERER \& BRUM DE PAULA, 2002, p. 125).

\section{O nacional e o regional}

A história revela, insistentemente, que o Brasil é um país republicano, unívoco, sustentado sob a égide um povo que fala uma só língua e que tem costumes próprios. Somos historicamente marcados pela tentativa de fixação de uma imagem de pátria brasileira, com uma cultura dita brasileira. Isso se dá, prioritariamente, para estabelecer uma relação de alteridade com o colonizador, revelando um Brasil que se distingue, pela língua e pela cultura, de Portugal. A imagem de uma pátria unificada também é 
constitutiva do imaginário gaúcho, bem como habita o imaginário do brasileiro pernambucano ou amazonense, muito embora ela não seja a única. É a partir dessa imagem de que todos são iguais que irrompe o diferente, porque o gaúcho sabe-se diferente do pernambucano (e vice-versa): é o diferente emergindo no interior do mesmo. Nesse espaço de constituição lingüística e cultural, alternam-se relações de identidade e de alteridade entre os sujeitos que são brasileiros, mas que também são gaúchos, ou pernambucanos, ou baianos, etc. Trata-se de se pensar o que é geral e o que é local, de se pensar o nacional e o regional, na produção dos efeitos de sentido.

Para mobilizarmos as noções de sentido e de efeito de sentido, precisamos compreender como elas se constituem em Análise do Discurso. Na perspectiva discursiva, tem-se o sentido não como algo que está dado, mas como o apagamento de uma constituição material que causa um efeito de já-lá, uma vez que a ideologia fornece sustentação à produção das evidências (ou efeitos de evidência), que se realizam em cada prática discursiva, levando o sujeito a crer na transparência da linguagem. Pêcheux (1995) já afirmava que o sentido não existe "em si mesmo"; e Foucault (1979)2 introduziu, por meio de seus trabalhos, a noção de "verdade local", a partir da qual o sentido funciona "localmente", e não universalmente. Paul Henry (1993a) salienta que o grande mérito desses dois autores está no fato de que ambos "tentaram estimular um procedimento suscetível de construir localmente certos fatos de sentido" (p. 162). Dessa citação, interessa-nos, em especial, o elemento que desloca as reflexões sobre a constituição dos sentidos no discurso: do universal para o local. Trata-se de pensar o sentido como um efeito de evidência ou de obviedade, produzido na ordem da língua, e que pode ser desconstruído na ordem do discurso, já que é na ordem da língua que se constrói o efeito de unidade do sujeito e do sentido. $\mathrm{E}$ tal unidade pode ser desconstruída, se passarmos para a ordem do discurso, na qual ocorre a interferência de outros elementos, que são exteriores à língua e que são igualmente constitutivos de sentidos.

$O$ efeito de sentido evidente se produz como efeito de verdade, na ilusória unidade do texto e do sujeito, o qual acredita poder controlar os sentidos sobre o que produz discursivamente. No entanto, se pensarmos esse efeito de obviedade posto como "local", vamos restringir seu funcionamento a uma Formação Discursiva

2 A edição original em francês é de 1976.

fragmentum, n. 15. Laboratório Corpus: UFSM, 2008. 
específica e aos sujeitos que nela se inscrevem. Tratar o sentido "localmente" implica considerar as contradições que the são inerentes e constitutivas, tais como: a) a multiplicidade de significados que advém de um mesmo significante; $b$ ) as relações entre o mesmo (a continuidade) e o diferente (a descontinuidade), no interior de uma mesma FD; c) a constituição mútua que se dá entre sujeito e sentido no discurso. Se pensarmos nas relações entre a Literatura Brasileira e a Literatura Sul-rio-grandense, vamos nos deparar com o diferente no interior do mesmo, sendo que a segunda é constitutiva da primeira. O gaúcho é também brasileiro, de forma que a literatura produzida aqui também se inscreve no espaço nacional, muito embora o espaço de circulação nem sempre explicite essa necessária relação entre sujeitos, entre línguas, entre culturas.

Assim sendo, o sentido se constitui em meio a contradições, até porque o sujeito que se projeta com ele, no discurso, é dotado de inconsciente e atravessado pela ideologia, o que contribui para que o sentido não seja dado como pronto, desde sempre, pois sua efetivação depende da posição que o sujeito assume "localmente" no plano ideológico, social, histórico e discursivo, pondo em relação o social e o ficcional, próprio do discurso literário.

$\mathrm{Na}$ verdade, há um lugar bem próprio, na sociedade gaúcha, destinado ao culto do regionalismo, em diferentes manifestações artístico-culturais, sobretudo na literatura, por sua materialidade escrita e discursiva; e essa peculiaridade gera condições de produção favoráveis à disciplinarização e à institucionalização da Literatura Sul-rio-grandense. Isso se deve ao fato de que o século XX é marcado pela vasta produção artística e literária que diferencia o que é nacional e o que é regional, fazendo deste último o constitutivo do primeiro. Dessa forma, como não há espaço para essa gritante diferença no processo de disciplinarização da Literatura, resta um lugar de fundação a ser preenchido pelas literaturas regionais.

A partir dessa institucionalização, as configurações e o estatuto da disciplina de Literatura Sul-rio-grandense sofrem alterações, no decorrer do tempo, e em conseqüência de toda a sorte de acontecimentos, conforme as condições de produção do "discurso sobre o gaúcho" (PETRI, 2004) se efetivaram. Esse processo não é mérito do Rio Grande do Sul, pois temos notícias de disciplinas que estudam regionalmente a Literatura Mineira, a Norterio-grandense, a Bahiana. Inclusive há um fato muito interessante, que é constitutivo da fundação do espaço institucionalizado da 
disciplina de Literatura Sul-rio-grandense, na UFRGS, em Porto Alegre, no final da década de 60 e início dos anos 70, do século XX: é pelo trabalho do professor Guilhermino César que, inicialmente, como catedrático de Literatura Brasileira ${ }^{3}$, e como homem sensível à demanda de uma literatura regional, própria do estado sulino, fundase a disciplina de Literatura Sul-rio-grandense, inicialmente ministrada por ele, um mineiro de formação acadêmica na área de Direito 4 . Essa "invenção" da disciplina não está alheia às aspirações da época, ela revela um processo de institucionalização do saber que há muito tempo vinha sendo produzido, constituindo, portanto, uma gama de obras representativas, dignas de ocuparem uma "cadeira" na universidade pública mais tradicional do Rio Grande do Sul, situada na capital.

Falar em Literatura Sul-rio-grandense, atualmente, é falar em uma literatura reveladora de uma atmosfera rural, própria à constituição do mito do gaúcho, que habita o imaginário coletivo; mas é também falar de toda a produção local que alcança ou não o espaço de circulação literário-nacional. Assim, salientamos os distanciamentos e as aproximações possíveis entre a Literatura Sulrio-grandense e a dita Literatura Regionalista Gauchesca, explicitando que a segunda é parte da primeira. De forma que é pela Literatura Regionalista Gauchesca que temos acesso às características temáticas bem próprias da constituição do imaginário sobre o "gaúcho"; é ela que revela a fundação e a manutenção do mito do gaúcho, como o "centauro dos pampas", ou o "monarca das coxilhas", etc. É pela Literatura Regionalista Gauchesca que temos acesso à vasta gama vocabular própria do "gaúcho", tal como o identificamos, na ordem da mitologia, da história e da literatura. A língua também marca o espaço da Literatura Regionalista Gauchesca, no interior da Literatura Sul-rio-grandense, porque essa língua ganhou um espaço institucionalmente constituído, estando cristalizada em inúmeras publicações de dicionários regionalistas, em vocabulários de termos gaúchos, ou ainda em glossários específicos que acompanham as obras.

$\mathrm{Na}$ verdade, estamos nos propondo também, com este trabalho, a refletir sobre as relações institucionais que se estabelecem, quando se disciplinariza a literatura regional do estado

\footnotetext{
3 A partir de 1962.

${ }^{4}$ Cf. afirma Luís Augusto Fischer, em entrevista, no dia 13/09/2006, realizada na UFRGS, Campus do Vale.
}

fragmentum, n. 15. Laboratório Corpus: UFSM, 2008. 
sulino, designada como Sul-rio-grandense. Ao denominar-se Sul-riograndense, ela abarca toda a produção literária de um estado brasileiro, considerando que, de uma forma ou de outra, a literatura produzida aqui se relaciona com a gauchesca, seja para negá-la e fundar um outro lugar; seja para revivê-la, em seus aspectos mais primitivos; seja para presentificá-la, através de novas máscaras. A produção literária do Rio Grande do Sul parte de um referente que está dado, e ele não se apaga pela emergência do novo, porque os mitos não morrem (ELIADE, 1972), de forma que eles podem sempre re-aparecer em outras faces.

Assim, se tomarmos as especificidades da língua constitutiva da Literatura Regionalista Gauchesca, poderemos perceber sua importância na construção da História das Idéias Lingüísticas do e no sul do Brasil. E são os instrumentos lingüísticos, sobretudo os currículos e os diários de classe, que ganham o funcionamento de documentos a serem lidos, constituindo nosso objeto de análise.

Não se tem a pretensão de julgar a constituição curricular das universidades, pois nosso objetivo de analista de discurso é o de observar a constituição das práticas discursivas e, nesse caso bem específico, estamos levando em conta que Língua e Literatura não podem estar compartimentalizadas em diferentes espaços, nas práticas sociais e na história, pois os sentidos se constituem nessas relações, integrando-as, significando e re-significando-as mutuamente. Da mesma forma, buscamos "detectar a incidência das interrupções, cuja posição e natureza são, aliás, bastante diversas" (FOUCAULT, 1995), no ensino da Literatura Sul-rio-grandense, nas Universidades pesquisadas (UFRGS, UFSM, etc.).

Investigar a instituição e a disciplinarização da Literatura Regional é reunir fatos de língua e de cultura locais que revelam nuances da constituição identitária de todo um grupo social, bem como contribuir com a História das Idéias Lingüísticas. Histórias de vida e história institucional se mesclam, e nos damos conta de que cabe mesmo à história suspender o acúmulo indefinido dos conhecimentos, permitindo que a escrita seja permeada de lacunas e saturações. É assim que se apresenta a memória. Entendemos que, ao estudarmos essa história, estamos identificando o lugar da disciplina na instituição, bem como a presença/ausência dos "saberes" abrigados, sob a instituída disciplina de Literatura Sul-riograndense, na história de vida de tantos egressos dos cursos de Letras. Nosso estudo revela também efeitos de sentido produzidos por deslocamentos e transformações, na área de Literatura Sul-rio- 
grandense, que intervêm na constituição curricular dos Cursos de Letras, pois há saberes próprios dessa disciplina ecoando em outros lugares, como as análises irão demonstrar.

Fazer um estudo sobre a presença/ausência da Literatura Sulrio-grandense, nos currículos do Curso de Letras da UFSM, implicou o estudo das relações estabelecidas, através dos tempos, entre essa disciplina e as demais disciplinas literárias e lingüísticas que, conforme nos mostra a história, entrecruzam-se de forma significativa (PETRI, 2004). Isso aparece na análise do currículo e dos diários de classe encontrados.

Apostamos na recuperação de um pouco da história das idéias que fazem do Curso de Letras o que ele é hoje, muito embora compreendamos que os resultados de nossa pesquisa tenham um funcionamento transitório, próprios do jogo de transmissões, retomadas, esquecimentos e repetições que constroem a memória, que constroem a história das idéias.

\section{A Literatura Regionalista Gaúcha e a produção de efeitos de sentidos}

A Literatura Regionalista Gaúcha é especialmente rica em elementos lingüísticos e culturais, que revelam uma caracterização ímpar, há muito tempo adotada, pelo falar coloquial de todo o grupo social que se denomina gaúcho. Essa língua própria do gaúcho aparece com muita força e vitalidade na literatura regionalista, revelando traços da origem de um povo, que se constituiu na relação com outros povos; o que pode ser observado, por exemplo, na abundância de empréstimos tomados de outras línguas, como é o caso da Língua Espanhola. O estudo da língua culta (oficial) pode produzir um processo discursivo histórico de apagamento de elementos lingüísticos fortemente presentes na língua coloquial ou ficcional; mas, por outro lado, tem o poder de estabelecer relações de semelhança e de dessemelhança lingüístico-cultural-literárias, que produzem uma linguagem regional, como é o caso da do gaúcho. Língua e Literatura constituem-se mutuamente (PETRI, 2005), revelando a produção da literatura própria a um grupo social.

Há um jogo de diferenças constitutivo da História das Idéias Lingüísticas, quando língua e literatura são concebidas e descritas em suas relações. São pelo menos 30 anos de história do curso de Letras da UFSM, com a disciplina que trata da literatura regional, e é seguindo os rastros dessa trajetória que nos deparamos com a 
disciplina sendo designada como Literatura Rio-grandense, omitindo o elemento definidor, que seria "Sul", já que o lugar onde ela se institui e funciona é próprio e lhe atribui sentidos. É interessante como o apagamento de "sul" fortalece a produção de efeitos de sentidos vinculados ao local, pois é somente sob tais condições de produção e tão somente neste lugar que é o próprio sul do país que se ministra esta disciplina. É pelas condições de produção, pelo momento histórico, pela posição-sujeito e pela formação discursiva que os sentidos são determinados, não estando presentes, pois, na língua, mas sendo constitutivos do discurso, do sujeito. A partir do nome da disciplina, dos currículos e dos diários de classe, então, buscamos reconstituir um esboço dessa história, avalizada pelo e no currículo; bem como no ementário que "tem sua especificidade, internamente, sua ordem discursiva se apóia sobre um suporte institucional" (SCHERER, 2005, p. 18).

A partir da leitura de Pêcheux (1995, p. 213), vamos nos deparar com a questão da prática discursiva já "inscrita no todo complexo contraditório-desigual-sobredeterminado das formações discursivas que caracteriza a instância ideológica em condições históricas dadas", configurando já o elenco nocional da AD. Ao construir o quadro teórico da AD, Pêcheux (1993a, p. 82) concebe o discurso como "efeito de sentidos entre os pontos A e B", ou seja, entre os interlocutores, sendo que esse efeito é produzido a partir da determinação de lugares sociais que os sujeitos ocupam. É preciso levar em conta ainda que a ideologia é um dos elementos determinantes dessas relações sociais entre os interlocutores, unindo-se a ela, de modo essencial, as condições de produção do discurso, as quais, por conseguinte, são históricas, uma vez que "as ideologias não são feitas de "idéias", mas de práticas" (PÊCHEUX, 1995 , p. 144). Nessa concepção, as condições de produção do discurso são determinantes do sentido, pois é a partir dessas condições (sociais, econômicas, ideológicas) que cada sujeito se posiciona diante do outro, produzindo efeitos de sentido.

A reflexão desses autores nos conduz a pensar que a noção de efeito de sentido seja mais adequada para o nosso trabalho, pois pensar em efeitos de sentido é, antes de mais nada, levar em conta os dois movimentos necessários para a sua efetivação no discurso: um que resulta dos efeitos de sentidos que o "eu" produz sobre o "outro", no e pelo discurso; e o outro que resulta da produção do discurso sobre o sujeito que o produziu. Assim, ao mesmo tempo em que o sujeito, ao produzir seu discurso, afeta, de alguma forma, seu 
interlocutor, ele também é afetado pelo processo discursivo que se constitui naquele momento social e ideologicamente determinado. Com a noção de efeito de sentido, Pêcheux consegue suplantar as restrições próprias de uma noção de sentido que estava vinculada ao que Jakobson teria denominado: "recebimento da mensagem" ou "transmissão de informações", que o discurso deveria trazer consigo, já que a linguagem serve para comunicar e para não comunicar (PÊCHEUX, 1995).

Ao admitirmos o efeito de sentido, estamos admitindo que sujeito e sentido constituem-se mutuamente, pois a significação que se produz na relação que existe entre eles não é dada como um produto pronto e acabado. Essa significação não está estritamente alienada ao significante, a sua realização plena (ou não) depende das condições de produção, ou seja, a significação se dá "localmente", no interior da prática discursiva. Então, a produção de efeitos de sentido ocorre na prática discursiva, de onde falam (Formação Discursiva) e se posicionam os interlocutores (Formação Ideológica).

Assim, ao mencionarmos os processos de produção de sentido que fazem com que a designação Literatura Rio-Grandense seja instituída, estamos mobilizando a noção de sentido própria à Análise de Discurso. De fato, estamos levando em conta que o sentido é um efeito que se produz na e pela prática discursiva. Da mesma forma, compreendemos que a história das idéias se faz pela história de vida dos sujeitos, pela recuperação das práticas discursivas que engendraram a construção e a institucionalização de saberes. Concordamos com Scherer (2002, p.15) quando diz que "a maioria de nossas instituições não acorda a devida importância a esse tipo de material (ementários, programas, história de vida profissional na formação da intelectualidade brasileira)" e, por isso, sentimos necessidade de conhecer um pouco mais da história das idéias que pode se revelar na análise de ementários, diários de classe, depoimentos de professores, resultados de trabalhos de pesquisa científica, etc., numa tentativa de recuperar a memória social (e que também é nossa!), com suas lacunas e saturações.

\section{Bibliografia}

ELIADE, Mircea. (1972) Mito e realidade. Trad. Pola Civelli. São Paulo: Perspectiva. 
FOUCAULT, Michel. (1979) A microfísica do poder. Trad. Roberto Machado. Rio de Janeiro: Graal.

. (1995) A arqueologia do saber. Trad. Luiz Felipe Baeta Neves. 4. ed. Rio de Janeiro: Forense Universitária.

HENRY, Paul. (1993a) Sentido, sujeito e origem. Trad. Eni Poulcinelli Orlandi. In: ORLANDI, Eni P. (Org.) Discurso fundador. Campinas, SP: Pontes. p. 151-162.

OLIVEN, Ruben George. (1992) A parte e o todo: a diversidade cultural no Brasil-nação. Petrópolis, RJ: Vozes.

ORLANDI, Eni Pulcinelli (Org.).(1988) Política Lingüística na América Latina. Campinas, SP: Pontes.

. (2001) História das Idéias Lingüísticas: construção do saber metalingüístico e constituição da língua nacional. Campinas, SP: Pontes; Cáceres, MT: Unemat Editora.

; GUIMARÃES, Eduardo. (Org.) (2002) Institucionalização dos estudos da linguagem: a disciplinarização das Idéias Lingüísticas. Campinas, SP: Pontes.

PAYER, Maria Onyce. (2001) O rural no espaço público urbano. In: ORLANDI, Eni Pulcinelli (Org.). Cidade Atravessada: os sentidos públicos no espaço urbano. Campinas, SP: Pontes. p. 165-174.

PÊCHEUX, Michel. (1993) Análise Automática do Discurso (AAD69). In: GADET, Françoise; HAK, Tony. (Orgs.) Por uma análise automática do discurso: uma introdução à obra de Michel Pêcheux. Trad. Bethânia Mariani [et al.]. Campinas,SP: Editora da UNICAMP. p. 61-161.

. (1994) Ler o arquivo hoje. In: ORLANDI, Eni pulcinelli. (Org.) Gestos de leitura: da história no discurso. Trad. Bethânia S. Mariani [et al.] Campinas, SP: Editora da UNICAMP. p. 55-64.

. (1995) Semântica e discurso: uma crítica a afirmação do óbvio. Trad. Eni P. Orlandi. 2. ed. Campinas, SP: UNICAMP.

PEDROSA, Célia. (2000) Ensino, literatura, cultura: o resgate da técnica. AZEREDO, José Carlos de.(Org.) (2000) Língua Portuguesa em debate: conhecimento e ensino. Petrópolis, RJ: Vozes. p. 250-255. 
PETRI, Verli (2004). Imaginário sobre o gaúcho no discurso literário: da representação do mito em Contos Gauchescos, de João Simões Lopes Neto, à desmitificação em Porteira Fechada, de Cyro Martins. Porto Alegre: UFRGS, Instituto de Letras. Tese de Doutorado.

. (2005) Língua e Literatura: por uma análise do discurso literário. Revista Expressão. CAL/UFSM, Santa Maria, Ano 9. V. 1. №1. p. 190-196.

RANCIÈRE, Jacques. (1995) Políticas da Escrita. Trad. Raquel Ramalhete.Rio de Janeiro: Editora 34.

SANTOS, Pedro Brum. (2005) Literatura e História Literária no Rio Grande do Sul. In: GUIMARÃES, Eduardo; BRUM DE PAULA, Miriam Rose. (Orgs.) Sentido e Memória. Campinas/SP: Pontes. p. 117-127.

SCHERER, Amanda Eloina. (2005) Lingüística no Sul: estudo das idéias e organização da memória. In: GUIMARÃES, Eduardo; BRUM DE PAULA, Miriam Rose. (Orgs.) Sentido e Memória. Campinas/SP: Pontes. p. 9-26.

; BRUM DE PAULA, Miriam. (2002) Memória e história das idéias: o ensino do francês no RS do fim do século XIX ao início do século XX. In: ORLANDI, Eni; GUIMARÃES, Eduardo. (Orgs.) Institucionalização dos estudos da linguagem. Campinas, SP: Pontes. p. 121-138.

ZILBERMAN, Regina. (1992) A literatura no Rio Grande do Sul. 3. ed. Porto Alegre: Mercado Aberto. 